\title{
Sorption of mercury onto waste material derived low-cost activated carbon
}

\author{
Jatindra N. Bhakta $\cdot$ Sukanta Rana $\cdot$ \\ Susmita Lahiri $\cdot$ Yukihiro Munekage
}

Received: 13 April 2014/ Accepted: 9 October 2014/Published online: 2 November 2014

(C) The Author(s) 2014. This article is published with open access at Springerlink.com

\begin{abstract}
The present study was performed to develop the low-cost activated carbon (AC) from some waste materials as potential mercury $(\mathrm{Hg})$ sorbent to remove high amount of $\mathrm{Hg}$ from aqueous phase. The ACs were prepared from banana peel, orange peel, cotton fiber and paper wastes by pyrolysis and characterized by analyzing physico-chemical properties and $\mathrm{Hg}$ sorption capacity. The Brunauer Emmett and Teller surface areas (cotton $138 \mathrm{~m}^{2} / \mathrm{g}$; paper $119 \mathrm{~m}^{2} / \mathrm{g}$ ), micropore surface areas (cotton $65 \mathrm{~m}^{2} / \mathrm{g}$; paper $54 \mathrm{~m}^{2} / \mathrm{g}$ ) and major constituent carbon contents (cotton $95.04 \%$; paper $94.4 \%$ ) were higher in ACs of cotton fiber and paper wastes than the rest two ACs. The Hg sorption capacities and removal percentages were greater in cotton and paper wastes-derived ACs compared to those of the banana and orange peels. The results revealed that elevated $\mathrm{Hg}$ removal ability of cotton and paper wastes-derived ACs is largely regulated by their surface area, porosity and carbon content properties. Therefore, ACs of cotton and paper wastes were identified as potential sorbent among four developed ACs to remove high amount of $\mathrm{Hg}$ from aqueous phase. Furthermore, easily accessible precursor material, simple preparation process, favorable physico-chemical properties and high
\end{abstract}

J. N. Bhakta $(\varangle) \cdot$ S. Rana $\cdot$ S. Lahiri

International Centre for Ecological Engineering, University of

Kalyani, Kalyani 741235, West Bengal, India

e-mail: 1snjbhakta@gmail.com

J. N. Bhakta $\cdot$ S. Rana $\cdot$ S. Lahiri

Ramnagar Institute of Rural Human Resource Development,

Purba Medinipur 721453, West Bengal, India

Y. Munekage

Department of Environmental Engineering, Faculty of

Agriculture, Kochi University, B200, Monobe, Nankoku, Kochi 783-8502, Japan
$\mathrm{Hg}$ sorption capacity indicated that cotton and paper wastes-derived ACs could be used as potential and lowcost sorbents of $\mathrm{Hg}$ for applying in practical field to control the severe effect of $\mathrm{Hg}$ contamination in the aquatic environment to avoid its human and environmental health risks.

Keywords Waste material · Pyrolysis - Activated carbon . Mercury $\cdot$ Sorption $\cdot$ SEM-EDS

\section{Introduction}

Mercury $(\mathrm{Hg})$ is a potent neurotoxin and priority hazardous pollutant (ATSDR 2007). It moves around the world in three key routes-(1) it is actively traded as a global commodity, (2) airborne $\mathrm{Hg}$ released by industrial activities can travel long distances before being deposited in waterways and (3) naturally occurring bacteria absorb $\mathrm{Hg}$ from aqueous phase and convert to its most toxic form, methyl-Hg, which then moves up the food chain. Thus, it contaminates the global environment and poses serious environmental and human health risks by bioconcentration, bioaccumulation and biomagnification phenomena. $\mathrm{Hg}$ and its derivatives can easily be adsorbed through the gastrointestinal tract, skin and lungs and can cause impairment of pulmonary function and kidney, chest pain and dyspnoea at high concentration (Berglund and Bertin 1969; Krishnamoorthi and Vishwanathan 1991; Bidstrup 1964; Eisler 1987; Horvat et al. 2003; Fang et al. 2004) and hence it is recognized as a dangerous and insidious poison (Bidstrup 1964). The U.S. Environmental Protection Agency reported that 630,000 newborns in America are at risk for unsafe levels of $\mathrm{Hg}$ exposure (Mahaffey 2004). 
Volcanic activity and weathering of rocks are the geogenic sources of $\mathrm{Hg}$; whereas coal burning, electronic, paper, pharmaceutical industries (Biester et al. 2002; Tack et al. 2005) chlor-alkali, paint, pulp and paper, oil refinery, electrical, rubber processing, and fertilizer industries (Krishnan and Anirudhan 2002; Kadirvelu et al. 2004) are major industrial sources for environmental contamination of $\mathrm{Hg}$. According to UN experts, between 3,100 and 3,900 metric tons of $\mathrm{Hg}$ are purchased around the world each year for various products and processes. The World Health Organization (WHO) also reported that between 25,000 and 125,000 tons of $\mathrm{Hg}$ were discharged into the environment in 1976 (Kothandaraman and Geetha 1997). Such a massive volume of $\mathrm{Hg}$ is supposed to be indiscriminately introduced into the environment through the industrial effluents. Hence, it poses serious threats to human and environmental health, thereby becoming a matter of vital concern. Therefore, the WHO sets up $0.001 \mathrm{mg} / \mathrm{L}$ concentration of $\mathrm{Hg}$ as drinking water permissible limit (WHO 2004) and Indian Standard Institution (ISI) sets up 0.001 and $0.01 \mathrm{mg} / \mathrm{L}$ concentrations of $\mathrm{Hg}$ for drinking and waste waters permissible limits, respectively, to control indiscriminate discharge of $\mathrm{Hg}$ into the environment. According to the USA's Environmental Protection Agency (EPA) permissible limit of $\mathrm{Hg}$ in wastewater is nil.

However, above apprehensive discussion assumes the importance of $\mathrm{Hg}$ removal from water and wastewater to reduce the excess $\mathrm{Hg}$ of waters to save life from severely hazardous and harmful impacts of $\mathrm{Hg}$. Though flux of $\mathrm{Hg}$ into the aquatic system has declined in recent years, there is still a lack of effective, easily accessible and low-cost means for the treatment of $\mathrm{Hg}$-contaminated wastewaters. Among various available methods for the removal of $\mathrm{Hg}$ from contaminated water, chemical precipitation, ion exchange, coagulation, solvent extraction, membrane filtration and nanofiltration, adsorption has been shown to be an economically feasible and easily applicable alternative using various adsorbents (Huang 1978; Koshima and Onishi 1980; Ma et al. 1992). Activated carbon (AC) is identified as a high capacity adsorbent to remove $\mathrm{Hg}$ from aqueous phase (Huang 1978; Koshima and Onishi 1980; Ma et al. 1992) due to the presence of its numerous porous structure, large active surface area, and good mechanical properties (Gergova et al. 1993; Girgis and Ishak 1999; Bhakta et al. 2009; Zabihi et al. 2009; Cai and Jia 2010). The various materials such as, peanut hull (Namasivayam and Periasamy 1993), jackfruit peel (Inbaraj and Sulochana 2001), coir pith (Namasivayam and Kadirvelu 1999), flax shive (Cox et al. 2000), sago waste (Kadirvelu et al. 2004), cotton stalks (Girgis and Ishak 1999), fruit shell (Gergova et al. 1993; Inbaraj and Sulochana 2006; Zabihi et al. 2009) and sewage sludge (De Filippis et al. 2013) have been used as carbonaceous precursors to produce AC for applying as
$\mathrm{Hg}$ removal sorbent. Besides, the scientists have applied various methods in the carbonization process to develop the AC from the precursor's materials and modification of $\mathrm{AC}$ to enhance the sorption capacity. The AC has been manufactured from carbonaceous materials of vegetable origin, such as wood, coal, peat, fruit stones, and shell by means of pyrolysis (Manocha 2003). Nabais et al. (2004) developed AC fibers by microwave heating from acrylic textile fibers. The cotton stalk can be used to produce high capacity AC by the processes of zinc chloride (Deng et al. 2009) and phosphoric acid (Girgis and Ishak 1999) activations. Kawasaki et al. (2012) proposed that the low-cost fibrous AC can be produced by heating process

Although, ACs have been developed from varieties of materials to adsorb $\mathrm{Hg}$ from aqueous phase, many of them are costly and/or inaccessible and/or ineffective in the practical field of application. In this point of view, the sorbent of low cost, high removal capacity, simple preparation technology and easy application method still has high demand. There is a need to develop low-cost sorbent using simple preparation process to control the pollution (Streat et al. 1995). Therefore, the aim of present study is to develop the AC from some low-cost materials for identifying as the potential and low-cost $\mathrm{Hg}$ adsorbent by physico-chemical and $\mathrm{Hg}$ sorption characterizations.

\section{Materials and methods}

Preparation of activated carbon from waste material (ACWM)

The present study used four types of waste-banana peel, orange peel, cotton fiber and paper as precursors to prepare the low-cost ACs of waste materials (ACWMs) following the carbonization method using microwave-assisted heating process (i.e., pyrolysis) (Menendez et al. 1999; Carrott et al. 2001; Kadirvelu et al. 2004; Chang-Xing et al. 2006; Nabais et al. 2004; Deng et al. 2009). The banana peel and orange peel wastes were collected from local market; cotton used for microbiological work and paper wastes were collected from laboratory waste bean. The procured wastes were properly washed under tap water to remove attached particulates, sprayed with distilled water and finally dried in sunlight. The $30 \mathrm{~g}$ of each dried waste was taken within a lidded porcelain cup which was placed inside the multimode microwave and heated at about $500{ }^{\circ} \mathrm{C}$ for $20 \mathrm{~min}$ to carbonize the employed waste. Infrared optical pyrometer was used to measure the temperature of the carbon bed during the microwave-assisted heating process. After cooling, the ACs of banana peel, orange peel, cotton fiber and paper wastes (herein called as $\mathrm{ACWM}_{\mathrm{B}}, \mathrm{ACWM}_{\mathrm{O}}, \mathrm{ACWM}_{\mathrm{C}}$ and $\mathrm{ACWM}_{\mathrm{P}}$ ) were crushed 
into powder and stored in sealed glass containers for using in subsequent studies.

Physical and chemical analysis of ACWM

The Brunauer Emmett and Teller (BET) surface area and porosity of developed ACWMs $\left(\mathrm{ACWM}_{\mathrm{B}}, \mathrm{ACWM}_{\mathrm{O}}\right.$, $\mathrm{ACWM}_{\mathrm{C}}$ and $\mathrm{ACWM}_{\mathrm{P}}$ ) were determined by adsorption of nitrogen at $-196{ }^{\circ} \mathrm{C}$ using Micromeristic ASAP 2000 instrument. The morphological and chemical properties of prepared ACWMs were analyzed by capturing images of surface morphology at three levels of magnification $(25 \times$, $2,000 \times$ and $10,000 \times)$ and analyzing the chemical composition using scanning electron microscopy (SEM) with a jeol model equipment coupled with energy dispersive spectroscopy (EDS) facility (JSM-6500F, JEOL) in the Center for Advanced Marine Core Research, Kochi University, Japan using the process followed by Bhakta and Munekage (2013).

Hg sorption experiment

The study of $\mathrm{Hg}$ absorption of prepared ACWM was performed in $15(200 \mathrm{~mL})$ glass bottles following batch operation mode in the laboratory. All glass bottles were filled with $100 \mathrm{~mL}$ water of $100 \mu \mathrm{g} / \mathrm{L} \mathrm{Hg}$ concentration prepared from standard stock solution of mercuric chloride $\left(\mathrm{HgCl}_{2}\right.$, Cica-Reagent, Kanto Chemical Co., Inc., Tokyo, Japan) and randomly divided into five batches having three replicates $(5 \times 3)$ for four types of $\mathrm{ACWM}\left(\mathrm{ACWM}_{\mathrm{B}}\right.$, $\mathrm{ACWM}_{\mathrm{O}}, \mathrm{ACWM}_{\mathrm{C}}$ and $\mathrm{ACWM}_{\mathrm{P}}$ ) sorbent and one control received no sorbent. The powder of each ACWM was added to each glass bottle of corresponding batch at the dosage of $0.05 \mathrm{~g} / \mathrm{L}$. The glass bottles were capped and shaken by mechanical shaker at the rate of 150 excursion/ $\min$ for the period of $5 \mathrm{~h}$ at $25^{\circ} \mathrm{C}$.

Sampling and analysis

Water samples $(1 \mathrm{~mL})$ were collected in $2 \mathrm{~mL}$ centrifuge tubes from each bottle at short interval initially and long interval afterwards, centrifuged and filtered by $0.5 \mu \mathrm{m}$ filter (Advantec, Tokyo, Japan). The filtered samples were used for Hg analysis using the RA-3 Mercury Analyzer (Nippon Instruments Corporation, Japan). The amount of $\mathrm{Hg}$ removed from water was calculated by quantifying the residual $\mathrm{Hg}$ content in water phase.

The $\mathrm{Hg}$ sorption capacity $(q, \mathrm{mg} / \mathrm{g})$ of ACWM was determined using the mass balance relationship Eq. (1) as below (Bhakta and Munekage 2013):

$q_{\mathrm{e}}=\left\{\left(C_{0}-C_{t}\right) \times V\right\} / M$
Table 1 Surface areas and porosities of resulting $\mathrm{ACWM}_{\mathrm{S}}$

\begin{tabular}{llll}
\hline ACWM & \multicolumn{2}{l}{ Surface area $\left(\mathrm{m}^{2} / \mathrm{g}\right)$} & \multirow{2}{l}{$\begin{array}{l}\text { Micropore } \\
\text { volume }(\mathrm{cc} / \mathrm{g})\end{array}$} \\
\cline { 2 - 3 } & BET & Micropore & \\
\hline $\mathrm{ACWM}_{\mathrm{B}}$ & 115 & 51 & 0.0628 \\
$\mathrm{ACWM}_{\mathrm{O}}$ & 109 & 43 & 0.0519 \\
$\mathrm{ACWM}_{\mathrm{C}}$ & 138 & 65 & 0.0910 \\
$\mathrm{ACWM}_{\mathrm{P}}$ & 119 & 54 & 0.0791 \\
\hline
\end{tabular}

where, $C_{0}$ and $C_{t}$ are water phase concentrations of $\mathrm{Hg}$ $(\mathrm{mg} / \mathrm{L})$ at time 0 and $t$, respectively, $V(\mathrm{~L})$ is the volume of the $\mathrm{Hg}$ solution and $M(\mathrm{~g})$ is the mass of ACWM.

The $\mathrm{Hg}$ removal percentage $\left(R_{\mathrm{e}}, \%\right)$ of ACWM from water phase was calculated using Eq. (2).

$R_{\mathrm{e}}=\left\{\left(C_{0}-C_{t}\right) / C_{0}\right\} \times 100$

where, $C_{0}$ and $C_{t}$ are the concentrations of $\mathrm{Hg}(\mathrm{mg} / \mathrm{L})$ in the solution at time 0 and $t$, respectively.

\section{Results and discussion}

Physical and chemical properties of ACWM

The BET surface areas $\left(109-138 \mathrm{~m}^{2} / \mathrm{g}\right)$, micropore surface areas $\left(43-65 \mathrm{~m}^{2} / \mathrm{g}\right)$ and micropore volumes (0.0519-0.0910) were varied in different resulting ACWMs (Table 1). The ACWMc and $\mathrm{ACWM}_{\mathrm{P}}$ exhibited higher BET surface areas, micropore surface areas and micropore volumes compared to those of the remaining ACWMs (Table 1).

The SEM images of the developed four ACWMs are shown in Fig. 1. The morphological properties, megascopic and microscopic textures of $\mathrm{ACWM}_{\mathrm{B}}, \mathrm{ACWM}_{\mathrm{O}}$, $\mathrm{ACWM}_{\mathrm{C}}$ and $\mathrm{ACWM}_{\mathrm{P}}$ are represented in three magnifying images $(25 \times, 2,000 \times$ and $10,000 \times)$. The $25 \times$ and $2,000 \times$ megascopic images show the clear shape and size of four ACWMs, whereas microscopic images of $10,000 \times$ clearly reveal the elaborate surface structures of all ACWMs.

The EDS analysis indicating the chemical composition of four ACWMs represented graphically in Fig. 2a-d. The data of detail chemical composition of ACWMs obtained from EDS analysis are also shown in Table 2. The major constituent of developed ACWMs was carbon (C) varied from 64.29 to $95.04 \%$. The $\mathrm{ACWM}_{\mathrm{C}}$ contains the highest percentage of $\mathrm{C}(95.04 \%)$ amongst the developed ACWMs. The phosphorus pentoxide $\left(\mathrm{P}_{2} \mathrm{O}_{5}, 5.24-5.59 \%\right)$ was also found in all ACWMs. Potassium oxide $\left(\mathrm{K}_{2} \mathrm{O}\right.$, $2.29-27.15 \%)$ and calcium oxide ( $\mathrm{CaO}, 0.68-3.16 \%)$ were observed only in $\mathrm{ACWM}_{\mathrm{B}}$ and $\mathrm{ACWM}_{\mathrm{O}}$, whereas $\mathrm{SiO}_{2}$ and $\mathrm{Cl}$ were exclusively found in $\mathrm{ACWM}_{\mathrm{B}}$. 
Fig. 1 SEM macro and micro images in three magnifying stages $(25 \times, 2,000 \times$ and $10,000 \times)$ of developed $\mathrm{ACWM}_{\mathrm{B}}, \mathrm{ACWM}_{\mathrm{O}}, \mathrm{ACWM}_{\mathrm{C}}$ and $\mathrm{ACWM}_{\mathrm{P}}$ employed in the present study

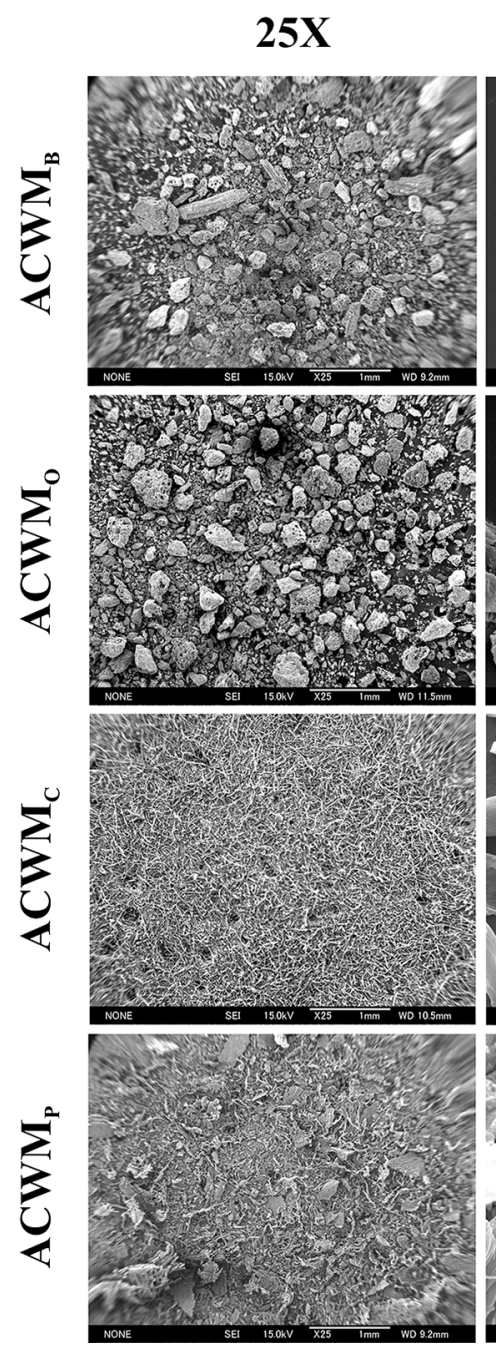

25X
2000X

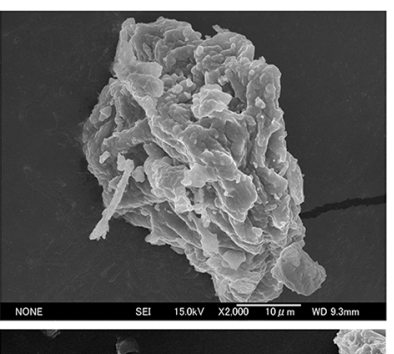

$10000 X$

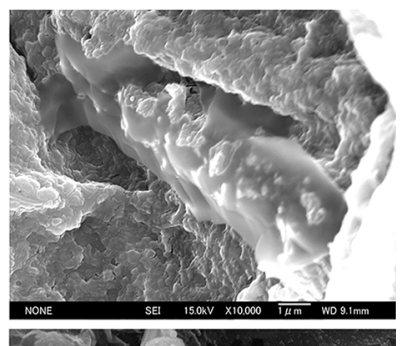

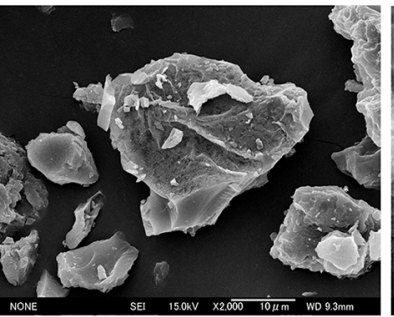
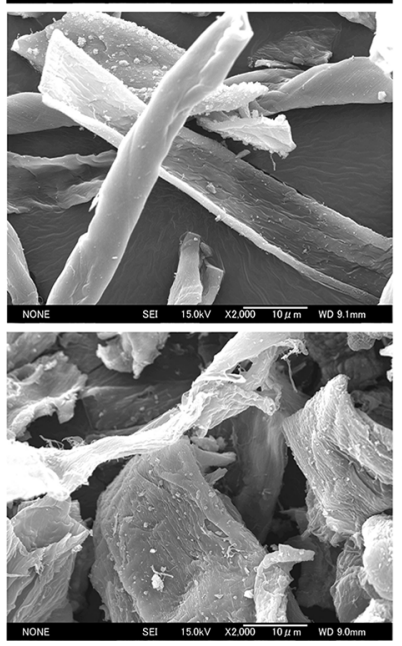
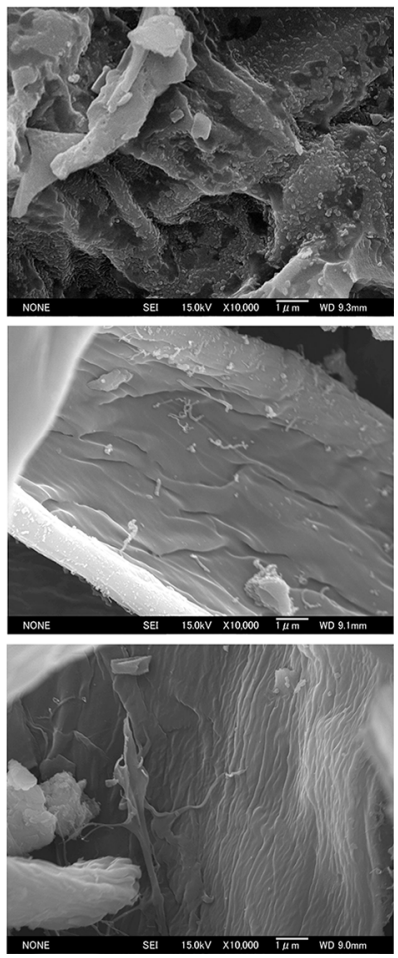

Results clearly demonstrated that the employed waste materials completely carbonized by pyrolysis phenomena at about $500{ }^{\circ} \mathrm{C}$ for $20 \mathrm{~min}$, because of the soft nature of waste materials and developed ACs having high surface and porous areas. The basic microstructure of the char with microporosity is formed around $500{ }^{\circ} \mathrm{C}$ (Sun et al. 1997). The AC manufacturing consists of a charring or carbonization step in which the most of non carbon material (and much of the carbon) is volatilized by pyrolysis (usually between 500 and $750{ }^{\circ} \mathrm{C}$ ) and obviously weight (60-70\%) is loosed (Girgis and Ishak 1999; Holland 1994; Sun et al. 1997). The present study clearly revealed that the higher $C$ containing ACWM exhibited the larger surface and porous areas developed by microwave heating process. The criteria of higher percentage of $\mathrm{C}$ as well as larger surface and porous areas would play significant role to increase the sorption capacity of ACWM. AC produced by the pyrolysis of carbonaceous materials of vegetable origin, such as wood, coal, peat, fruit stones, and shell or synthetic polymer followed by the activation of the chars obtained from them (Manocha 2003). The AC of highly developed porosity and correspondingly large surface area is obtained only by activating the carbonized material either by physical or chemical activation (Menendez et al. 1999). The AC possesses extraordinarily large surface area and pore volume those give it a unique adsorption capacity (Manocha 2003). The surface chemistry and pore size distribution of AC are highly responsible for adsorption process (Radovic 2001).

$\mathrm{Hg}$ sorption capacity and mechanism

The $\mathrm{Hg}$ sorption capacity varied from 0 to $1.84 \mathrm{mg} / \mathrm{g}$ in control and four ACWMs developed by carbonization phenomena (Fig. 3). There was a sharp increasing trend of $\mathrm{Hg}$ sorption in four ACWMs at the $0.5 \mathrm{~h}$ period and it showed steady state thereafter as time progressed. The $\mathrm{Hg}$ sorption capacities were higher in $\mathrm{ACWM}_{\mathrm{C}}(1.84 \mathrm{mg} / \mathrm{g})$ and $\mathrm{ACWM}_{\mathrm{P}}(1.8 \mathrm{mg} / \mathrm{g})$ compared to those of the $\mathrm{ACWM}_{\mathrm{B}}$ and $\mathrm{ACWM}_{\mathrm{O}}$. The removal percentage of $\mathrm{Hg}$ 
a

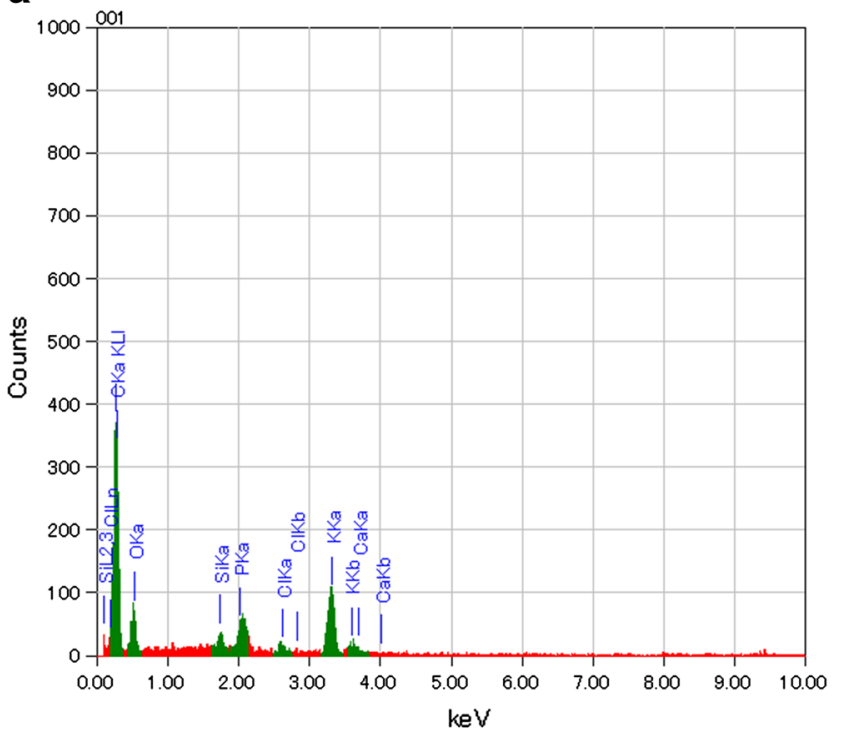

C

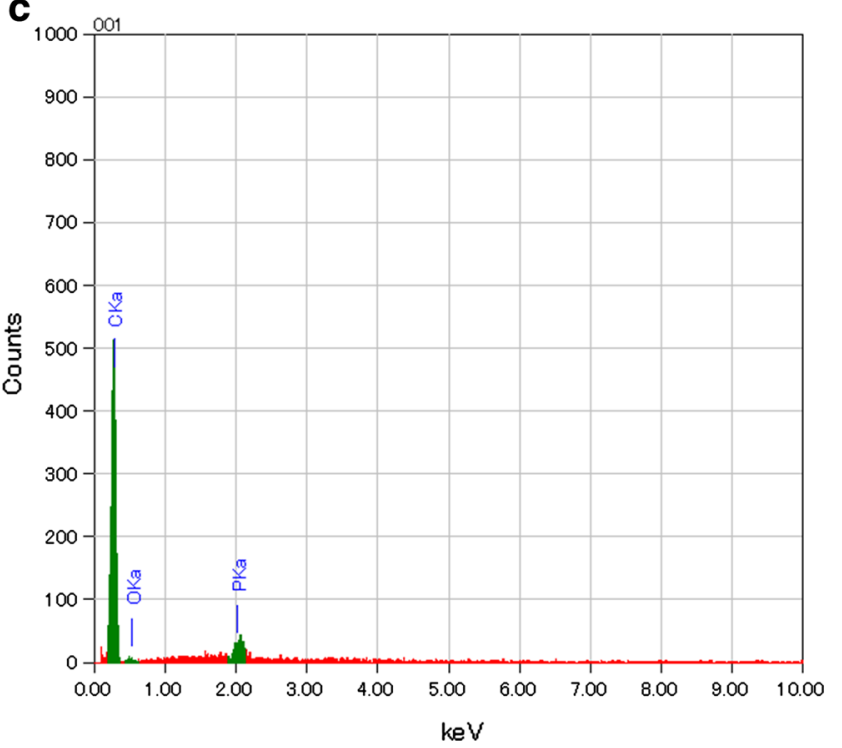

b

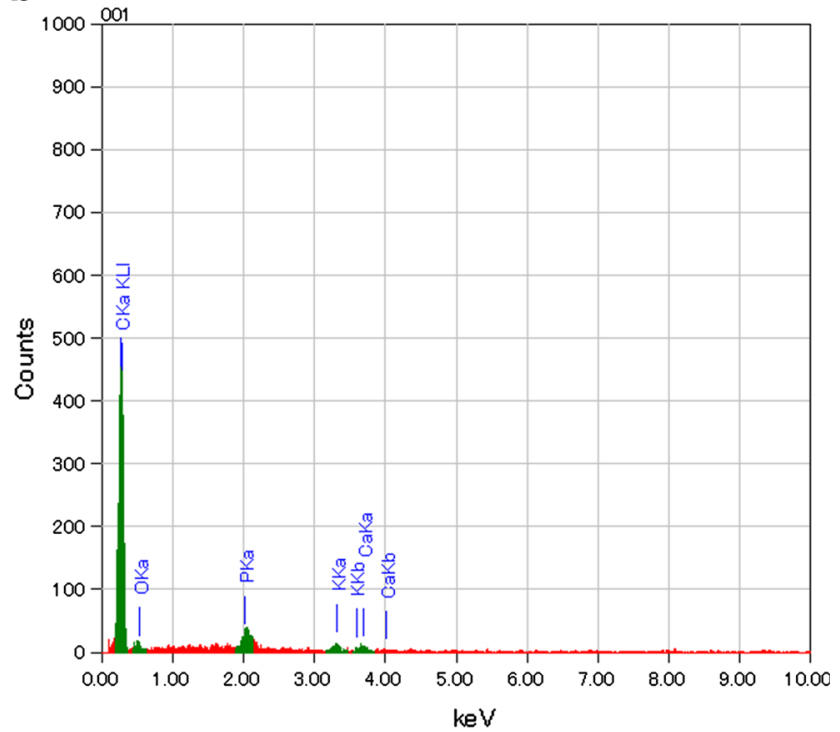

d

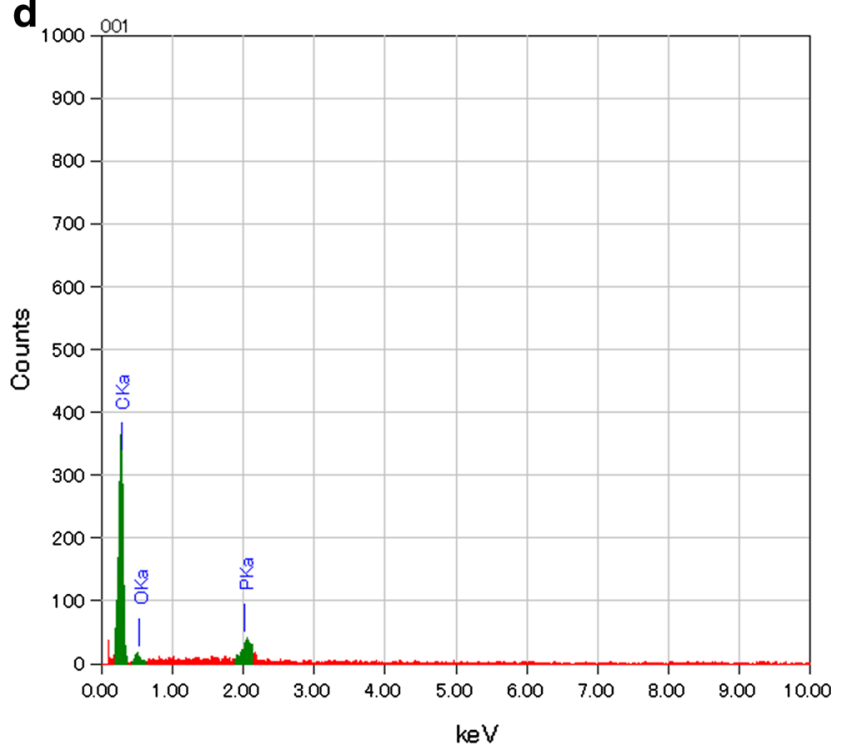

Fig. 2 EDS spectrum of developed $\mathrm{ACWM}_{\mathrm{B}}(\mathbf{a}), \mathrm{ACWM}_{\mathrm{O}}(\mathbf{b}), \mathrm{ACWM}_{\mathrm{C}}(\mathbf{c})$ and $\mathrm{ACWM}_{\mathrm{P}}(\mathbf{d})$ employed in the experiment

Table 2 Percentage composition of chemical constituents of four developed ACWMs employed for aqueous $\mathrm{Hg}$ sorption study

\begin{tabular}{lrlll}
\hline \multirow{2}{*}{$\begin{array}{l}\text { Chemical composition } \\
\text { wt })\end{array}$} & \multicolumn{5}{l}{ Types of activated carbons } \\
\cline { 2 - 5 } & $\mathrm{ACWM}_{\mathrm{B}}$ & $\mathrm{ACWM}_{\mathrm{O}}$ & $\mathrm{ACWM}_{\mathrm{C}}$ & $\mathrm{ACWM}_{\mathrm{P}}$ \\
\hline $\mathrm{C}$ & 64.29 & 89.0 & 95.04 & 94.4 \\
$\mathrm{P}_{2} \mathrm{O}_{5}$ & 5.29 & 5.24 & 5.57 & 5.59 \\
$\mathrm{~K}_{2} \mathrm{O}$ & 27.15 & 2.59 & - & - \\
$\mathrm{SiO}_{2}$ & 4.59 & - & - & - \\
$\mathrm{Cl}$ & 1.29 & - & - & - \\
$\mathrm{CaO}$ & 0.08 & 3.16 & - & - \\
\hline
\end{tabular}

ranged from 0 to $92 \%$ in control and four ACWMs. Likewise, the $\mathrm{ACWM}_{\mathrm{C}}$ and $\mathrm{ACWM}_{\mathrm{P}}$ also showed greater percentage of $\mathrm{Hg}$ removal than those of the $\mathrm{ACWM}_{\mathrm{B}}$ and $\mathrm{ACWM}_{\mathrm{O}}$ (Fig. 4).

The $\mathrm{Hg}$ removal capacity and percentage clearly revealed that the higher $\mathrm{C}$ containing ACWM showed higher $\mathrm{Hg}$ sorption capacity. The relationship between $\mathrm{Hg}$ sorption percentage and BET surface area of four ACWMs proved that highest $\mathrm{Hg}$ sorption capacities of ACWMc and $\mathrm{ACWM}_{\mathrm{P}}$ are significantly governed by the larger surface area as well as porosity. In contrary, those ACWMs composed by other components (such as, $\mathrm{K}_{2} \mathrm{O}, \mathrm{CaO}, \mathrm{SiO}_{2}$ and 


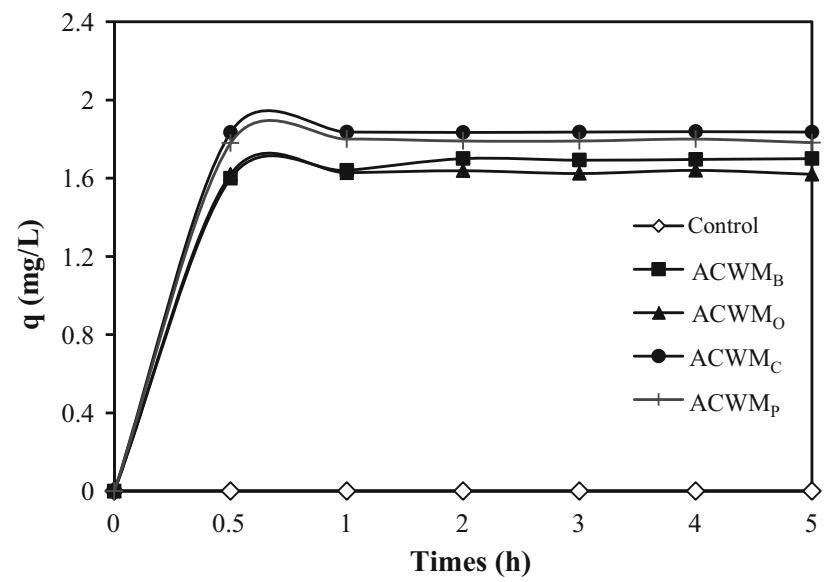

Fig. $3 \mathrm{Hg}$ sorption criteria of four developed ACWMs in water medium

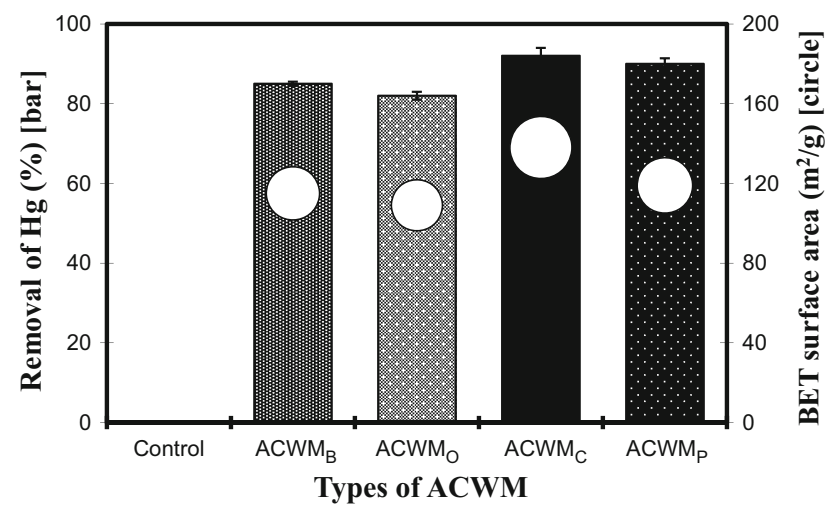

Fig. 4 Relationship between $\mathrm{Hg}$ sorption percentage (bar) and BET surface area (white circle within the bar) of four derived ACWMs in aqueous phase

$\mathrm{Cl}$ ) along with the major constituent $\mathrm{C}$, are associated with lower/reduced rate of $\mathrm{Hg}$ sorption. The chemical composition of the raw material influences the surface chemistry and offers a potentially lower cost method for adjusting the properties (especially sorption property) of activated carbons (Radovic 2001; Jabit 2007). It can also be explained herein that the $\mathrm{K}_{2} \mathrm{O}, \mathrm{CaO}, \mathrm{SiO}_{2}$ and $\mathrm{Cl}$ constituents of the ACWM are responsible to inhibit its $\mathrm{Hg}$ sorption proficiency, because some binding sites/surface functional groups of ACWM are neutralized by its constituents, $\mathrm{K}_{2} \mathrm{O}$, $\mathrm{CaO}, \mathrm{SiO}_{2}$ and $\mathrm{Cl}$. Thus, these preoccupied positive $\mathrm{K}, \mathrm{Ca}$ and $\mathrm{Si}$ ions of ACWM create an action of ionic repulsion to $\mathrm{Hg}$ ions on the surface of the ACWM. Langmuir proposed that the interaction of both positively charged adsorbent and adsorbate is electrostatic repulsion (Langmuir 1918). It is also well known that various surface functional groups containing oxygen, nitrogen and other heteroatoms have been identified on activated carbon. Because activated carbons have a large porosity and numerous disordered spaces, heteroatoms readily combine on the surface during

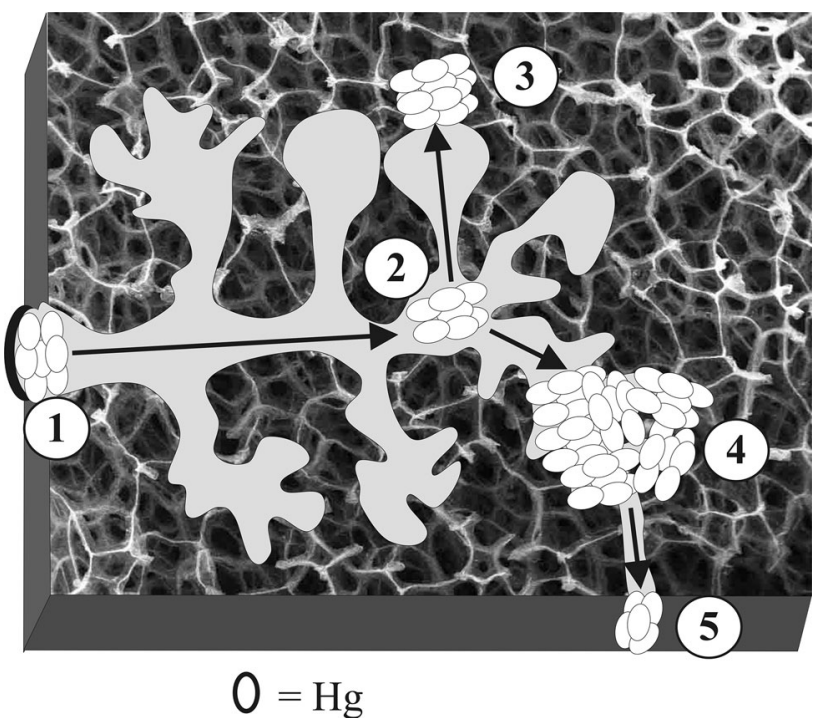

Fig. $5 \mathrm{Hg}$ binding and mechanism of diffusion through the porous network of AC. The process includes following five steps: 1 outersphere complex formation, 2 inner-sphere complex formation, 3 lateral diffusion, 4 particle growth and 5 diffuse back to the solution after saturation of adsorption

the manufacturing processes (carbonization and activation). Heteroatoms are incorporated into the network and are also bound to the periphery of the planes. With respect to present study, the heteroatoms' property at the surfaces of ACWM due to the presence of K, Ca and Si probably inhibits the binding of $\mathrm{Hg}$.

The sorption process of activated carbon is considered primarily physical rather than chemical in the vast surface areas and microporous regions by weak electrical forces known as Van der Waals bonds. The solute transfers from the bulk liquid to the surface layer of a particle by this force and diffusion of the solute is occurred from surface to inner regions of the adsorbent particle through/across the surface. This phenomenon clearly indicating that greater surface and micropore areas of $\mathrm{ACWM}_{\mathrm{C}}$ and $\mathrm{ACWM}_{\mathrm{P}}$ play principal role in removing highest amount of $\mathrm{Hg}$ from aqueous phase rather than other influencing factors discussed herein. Though the study was not performed, the following mechanism of $\mathrm{Hg}$ sorption onto ACWM can be hypothesized from the above-illustrated phenomenon: $\mathrm{Hg}$ is bound at the surface and form outer-sphere complex; and moves to the inner part of the pores through the network of micro channels by forming inner-sphere complex, lateral diffusion and particle growth; and finally adsorbed $\mathrm{Hg}$ can diffuse back to the solution after saturation of adsorption (Fig. 5). This type of adsorption mechanism has also been proposed by Bharathi and Ramesh (2013). Adsorption is usually modeled by isotherms which relate the relative concentrations of solute adsorbed to the solid and in solution. Though, it was not considered in the present 
investigation, the isotherm and kinetics studies of $\mathrm{Hg}$ sorption should be performed in further study to evaluate and characterize the detailed $\mathrm{Hg}$ sorption potentiality and mechanism of best cotton and paper wastes-derived ACs.

\section{Management of spent AC}

The AC itself is not a hazardous material (USSPA 1998). After sorption of hazardous materials (such as $\mathrm{Hg}$ ), it is considered as hazard material (Shapiro 1996). The Hg can be separated from the $\mathrm{Hg}$ loaded spent $\mathrm{AC}$ by the desorption process using some agents [such as-nitric acid, hydrochloric acid, Ethylenediaminetetraacetic acid (EDTA), etc.] (Young 1995; Anagnostopoulos et al. 2012). Therefore, the $\mathrm{AC}$ carbon can be recycled and reused easily to control further environmental health hazardous impact of spent AC.

\section{Conclusions}

This study developed low-cost AC from waste materials by pyrolysis method using the microwave-assisted heating process. The $\mathrm{Hg}$ sorption capacities were higher in $\mathrm{AC}$ of cotton fiber $\left(\mathrm{ACWM}_{\mathrm{C}}, 1.84 \mathrm{mg} / \mathrm{g}\right)$ and paper $\left(\mathrm{ACWM}_{\mathrm{P}}\right.$, $1.8 \mathrm{mg} / \mathrm{g}$ ) wastes having larger BET surface area, micropore surface area, micropore volume and carbon content. Moreover, the relationship between physico-chemical properties and $\mathrm{Hg}$ sorption capacity indicated that higher surface area, porosity and carbon content are largely responsible for the sorption of greater amount of $\mathrm{Hg}$ onto developed ACWM. The Hg sorption study clearly identified that ACs of cotton fiber and paper wastes are best sorbents of $\mathrm{Hg}$ amongst the four produced ACs. Furthermore, easily accessible precursor materials, simple preparation process, favorable physico-chemical properties and high $\mathrm{Hg}$ sorption capacity suggested that activated carbons of wastes materials could be used as a low-cost sorbent of $\mathrm{Hg}$ for applying in practical field. Finally, it may be concluded that the cotton fiber and paper wastes-derived activated carbons would be a potential and low-cost $\mathrm{Hg}$ adsorbing medias in aqueous phase.

\begin{abstract}
Acknowledgments This work is financially supported by the Japan society for the Promotion of science, Govt. of Japan bearing the JSPS research Grant No. 20380181. The authors are grateful to Dr. Yuhji Yamamoto for extending his kind cooperation in the Physico-chemical analysis of AC.
\end{abstract}

Conflict of interest The author declares that there is no conflict of interests regarding the publication of this article.

Open Access This article is distributed under the terms of the Creative Commons Attribution License which permits any use, distribution, and reproduction in any medium, provided the original author(s) and the source are credited.

\section{References}

Anagnostopoulos VA, Manariotis ID, Karapanagioti HK, Chrysikopoulos CV (2012) Removal of mercury from aqueous solutions by malt spent rootlets. Chem Eng J 213:135-141

ATSDR (Agency for Toxic Substances and Disease Registry) (2007) CERCLA priority list of hazardous substances. Agency for Toxic Substances and Disease Registry, Atlanta. http://www. atsdr.cdc.gov/cercla/07list.html. Accessed 3 Dec 2007

Berglund F, Bertin M (1969) Chemical fallout. Thomas Publishers, Springfield

Bhakta JN, Munekage Y (2013) Identification of potential soil adsorbent for the removal of hazardous metals from aqueous phase. Int J Environ Sci Technol 10:315-324

Bhakta JN, Md Salim, Yamasaki K, Munekage Y (2009) Mercury adsorption stoichiometry of ceramic and activated carbon from aqueous phase under different $\mathrm{pH}$ and temperature. ARPN J Eng Appl Sci 4:52-59

Bharathi KS, Ramesh ST (2013) Removal of dyes using agricultural waste as low-cost adsorbents: a review. Appl Water Sci 3:773-790

Bidstrup PC (1964) Toxicity of mercury and its compounds. Elsevier, Amsterdam

Biester H, Muller G, Scholer HF (2002) Estimating distribution and retention of mercury in three different soils contaminated by emissions from chlor-alkali plants: part I. Sci Total Environ 284:177-189

Cai JH, Jia CQ (2010) Mercury removal from aqueous solution using coke-derived sulfur-impregnated activated carbons. Ind Eng Chem Res 49:2716-2721

Carrott PJM, Nabais JMV, Ribeiro Carrott MML, Men endez JA (2001) Thermal treatments of activated carbon fibres using a microwave furnace. Microporous Mesoporous Mater 47:243-252

Chang-Xing $\mathrm{Hu}$, Jin-song Zhou, Zhong-yang Luo, Sheng He, Guangkai Wang, Ke-fa Cen (2006) Effect of oxidation treatment on the adsorption and the stability of mercury on activated carbon. J Environ Sci 18:1161-1166

Cox M, El-Shafey EI, Pichugin AA, Appleton Q (2000) Removal of mercury(II) from aqueous solution on a carbonaceous sorbent prepared from flax shive. J Chem Technol Biotechnol 75:427-435

De Filippis P, Di Palma L, Petrucci E, Scarsella M, Verdone N (2013) Production and characterization of adsorbent materials from sewage sludge by pyrolysis. Chem Eng Trans 32:205-210

Deng H, Yang L, Tao G, Dai J (2009) Preparation and characterization of activated carbon from cotton stalk by microwave assisted chemical activation-application in methylene blue adsorption from aqueous solution. J Hazard Mater 166:1514-1521

Eisler R (1987) Mercury hazards to fish, wildlife, and invertebrates: a synoptic review. U.S. Fish Wildl Serv Biol Rep 85:1-10

Fang F, Wang Q, Li J (2004) Urban environmental mercury in Changchun, a metropolitan city in Northeastern China: source, cycle, and fate. Sci Total Environ 330:159-170

Gergova K, Petrov N, Minkova V (1993) A comparison of adsorption characteristics of various activated carbons. J Chem Technol Biotechnol 56:77-82

Girgis BS, Ishak MF (1999) Activated carbon from cotton stalks by impregnation with phosphoric acid. Mater Lett 39:107-114

Holland KM (1994) Producing active carbon using microwave discharge. US Patent 5,364,821

Horvat M, Nolde N, Fajon V, Jereb V, Logar M, Lojen S (2003) Total mercury, methylmercury and selenium in mercury polluted areas in the province Guizhou, China. Sci Total Environ 304:231-256 
Huang CP (1978) Chemical interactions between inorganic and activated carbon. In: Cheremisinoff PN, Ellerbush F (eds) Carbon adsorption handbook. Ann Arbor Science, Ann Arbor, pp 281-329

Inbaraj BS, Sulochana N (2001) Utilisation of an agricultural waste, jack fruit peel for the removal of $\mathrm{Hg}(\mathrm{II})$ from aqueous solution. In: Mersky RL (ed) Proceeding of 17th International Conference on Solid Waste Technology and Management, Philadelphia, pp 802-811

Inbaraj BS, Sulochana N (2006) Mercury adsorption on a carbon sorbent derived from fruit shell of Terminalia catappa. J Hazard Mater B133:283-290

Jabit NB (2007) The production and characterization of activated carbon using local agricultural waste through chemical activation process. Master Thesis, School of Material and Mineral Engineering, USM, Malaysia

Kadirvelu K, Kavipriya M, Karthika C, Vennilamani N, Pattabhi S (2004) Mercury(II) adsorption by activated carbon made from sago waste. Carbon 42:745-752

Kawasaki N, Tominaga H, Ogata F, Inoue K, Kankawa M (2012) Development of novel carbon fiber produced from waste fiber by carbonization. J Oleo Sci 61:593-600

Koshima H, Onishi H (1980) Collection of mercury from artificial sea-water with activated carbon. Talanta 27:795-799

Kothandaraman H, Geetha S (1997) Principle of environmental chemistry. B.I. Publication Pvt. Ltd., India

Krishnamoorthi CR, Vishwanathan P (1991) Toxic metal in the Indian environment. Tata McGraw Hill Publishing Co., Ltd., New Delhi

Krishnan KA, Anirudhan TS (2002) Removal of mercury (II) from aqueous solutions and chlor-alkali industry effluent by steam activated and sulfurised activated carbons prepared from bagasse pith: kinetics and equilibrium studies. J Hazard Mater 92:161-183

Langmuir I (1918) Adsorption of gases on plane surfaces of glass, mica and platinum. J Am Chem Soc 40:1361-1403

Ma X, Subramanian KS, Chakrabarti CL, Guo R, Cheng J, Lu Y, Pickering WF (1992) Removal of trace mercury (II) from drinking water: sorption by granular activated carbon. J Environ Sci Health 27:1389-1404

Mahaffey KR (2004) "Methylmercury: epidemiology update," presentation at the Fish Forum, San Diego. http://www.epa.gov/
waterscience/fish/forum/2004/presentations/Monday/mahaffey. pdf

Manocha SM (2003) Porous carbons. Sadhana, Printed in India. 28:335-348

Menendez JA, Menendez EM, Iglesias MJ, Garcia A, Pis JJ (1999) Modification of the surface chemistry of active carbons by means of microwave-induced treatments. Carbon 37:1115-1121

Nabais JMV, Carrott PJM, Ribeiro Carrott MML, Menendez JA (2004) Preparation and modification of activated carbon fibres by microwave heating. Carbon 42:1315-1320

Namasivayam C, Kadirvelu K (1999) Uptake of mercury(II) from wastewater by activated carbon from an unwanted agricultural solid by-product: coirpith. Carbon 37:79-84

Namasivayam C, Periasamy K (1993) Bicarbonate-treated peanut hull carbon for mercury (II) removal from aqueous solution. Water Res 27:1163-1168

Radovic LR (2001) Chemistry and physics of carbon. Marcel Dekker, New York, p 416

Shapiro MH (1996) How treating filtration media comparable to activated carbon would be permitted under RCRA. Letter to S. M. Churbock (Envirotrol), USEPA, Washington, 1996. http:// yosemite.epa.gov/osw/rcra.nsf/documents/3A7C832687A92576 852565DA006F05D9. Accessed 10 July 2002

Streat M, Partick W, Camporroperex MJ (1995) Sorption of phenol and pentachlorophenol from water using conventional and novel activated carbons. Water Res 29:467-472

Sun J, Hippo EJ, Marsh H, O'Brien WS, Crelling JC (1997) Activated carbon produced from an Illinois basin coal. Carbon 35:341-352

Tack FMG, Vanhaesebroeck T, Verloo MG, Rompaey KV, Ranst EV (2005) Mercury baseline levels in Flemish soils (Belgium). Environ Pollut 134:173-179

USSPA (1998) EPCRA Section 313 Reporting Guidance for Food Processors. EPA Office of Pollution Prevention and Toxics, Washington, DC

WHO (2004) Guidelines for drinking water quality, 3rd edn edn. World Health Organization, Geneva

Young K (1995) The adsorption and desorption characteristics of EDTA-chelated copper ion by activated carbon. Sep Sci Technol 30:899-915

Zabihi M, Ahmadpour A, Asl AH (2009) Removal of mercury from water by carbonaceous sorbents derived from walnut shell. J Hazard Mater 167:230-236 